\title{
DISCURSO, DISCURSO MEU, DIGA-ME: QUEM SOU EU? A REPRESENTAÇÃO SOCIAL DE RESISTÊNCIA DA PRESIDENTA DILMA ROUSSEFF EM TEMPOS DE CRISE
}

Rodrigo dos Santos Camilo (UnB) ${ }^{1}$

Esta pesquisa social discursiva crítica tem como propósito a investigação do modo como a presidenta da República do Brasil, Dilma Rousseff, construiu sua representação social de resistência no ano de 2015. O corpus é composto de discursos oficiais da chefe de governo. A análise é alicerçada nos pressupostos principais da Análise de Discurso Crítica (ADC), sobretudo na concepção proposta por Norman Fairclough $(2001 ; 2003)$ e Pedro (1998); na Teoria da Representação Social (TRS), nas bases de Guareschi e Jovchelovitch (2013), de Minayo (2013); em conexão com a Representação de Atores Sociais, segundo van Leeuwen (1998). A metodologia é qualitativa e as categorias analíticas são adotadas de van Leeuwen (1998). Os resultados revelaram que a presidenta da República, no ano de 2015, representou-se com dupla face: de um lado, como membro ativo e principal do corpo social formado por todos os brasileiros; por outro lado, mostrou-se como agente, atuando como protagonista da cena sociopolítica do Brasil.

Palavras-chave: Análise de Discurso Crítica (ADC); Representação Social; Discurso Político.

This critical social discourse research aims to investigate a) how DilmaRousseff, the President of the Federative Republic of Brazil, built her social representation of resistance in the course of 2015. The corpus comprises of the official speeches by the Rousseff. The analysis is based on the main assumptions of the Critical Discourse Analysis (CDA), particularly in the conception by Norman Fairclough $(2001 ; 2003)$ andPedro (1998); on the Theory of Social Representation as in Guareschi and Jovchelovitch (2013) and Minayo (2013); and in connection with Social Actors Representation by van Leeuwen (1998). The methodology is qualitative, while the analytic categories follow van Leeuwen (1998). Results show that President Rousseff represented herself in a dual role in 2015: on the one side as an active, leading member of the social body formed by all Brazilians; on the other side, as an agent that acts as protagonist of the Brazilian sociopolitical scene.

Keysword:Critical: Discourse Analysis (CDA); Social Representation; Political Discourse.

${ }^{1}$ Mestre em Linguística pela Universidade de Brasília na área de Linguagem e Sociedade. Especialista em Revisão de Texto pelo Centro Universitário de Brasília e Graduado em Letras - Português/Inglês pela Universidade Paulista. Professor no curso de Letras EAD da Universidade de Brasília. Pesquisa discursos, representações sociais, ideologias e identidades sociais. 


\section{Compreendendo a proposta}

Este trabalho é derivado da minha dissertação de Mestrado em Linguística, defendida no ano de 2016, sob o título Análise Discursiva Crítica da representação social de resistência da Presidenta da República do Brasil em tempos de crise. Sendo assim, este artigo tem o propósito de apresentar uma das partes que representa a essência da pesquisa que realizei.

A prática política tem papel fundamental na estruturação, na organização e na manutenção da vida em sociedade. No Brasil, vivemos numa democracia e isso nos concede o direito de eleger, por meio de voto direto, alguns de nossos compatriotas para atuar tanto na administração e no desenvolvimento das instâncias que compõem a vida social, como também na representação dos direitos e das necessidades da população.

Por meios das diversas interações sociais e das manifestações de opiniões, percebe-se que, numa parcela considerável da população brasileira, permeia o entendimento de que "política não se discute”. Esse pensamento, muitas vezes, é usado como justificativa para que, por exemplo, numa conversa cotidiana, as pessoas não reflitam, questionem ou avaliem a prática daqueles que foram eleitos como seus representantes.

Outro ponto a ser considerado é que o discurso constitui-se como um frutífero cenário de atuação dos políticos. É por meio do discurso que o ser e o fazer, no mundo social, acontecem. Dessa maneira, quando os membros de uma sociedade não participam, efetivamente, da prática política e não atuam em suas posições, cooperam para que o sistema permaneça marcado por falhas, desigualdades, ações de corrupção e retrocessos.

Nesse panorama, o recorte da realidade político-social que faço para este trabalho é a atuação do principal ator político brasileiro: o presidente da República, que é responsável pelas funções de chefe de Estado e de chefe de governo. Devido a isso, os frutos de sua atuação, como governo federal, estão intimamente relacionados à manutenção e à melhoria da vida de todos os sujeitos.

Nesse sentido, apresento aqui parte dos resultados de uma pesquisa social crítica que teve como propósitos responder aos seguintes questionamentos: 
- de que modo a presidenta da República do Brasil, Dilma Rousseff, por meio de seus discursos oficiais, construiu sua representação social no ano de 2015?

- qual o resultado que a ação representacional da chefe de governo constituiu diante de um cenário marcado por crise política, econômica e social?

Para alcançar as respostas dessas questões, neste artigo, analiso um dos discursos oficiais da presidenta Dilma proferido durante o ano de 2015. As teorias que vivificarão e embasarão esta investigação serão a perspectiva da Análise de Discurso Crítica (ADC) de Fairclough (2001; 2003) e de Pedro (1998); a qual me possibilitará estabelecer diálogo com a Teoria da Representação Social (TRS) nas bases de Guareschi e Jovchelovitch (2013) e de Minayo (2013); em conexão com a Representação de Atores Sociais, segundo van Leeuwen (1998).

Análise de Discurso Crítica: instrumento de investigação linguístico-social para promover a mudança

A Análise de Discurso Crítica ( $A D C$ ) é uma forma de promover pesquisa social crítica. Essa modalidade de investigação trata de questões como estas: o modo como as sociedades disponibilizam e suprem as pessoas com possibilidades e recursos que dão sentido e satisfação às suas vidas; como as sociedades produzem meios que submetem os indivíduos às desigualdades, à pobreza e à desestabilidade; e quais os caminhos existentes que podem gerar mudanças sociais que reduzam esses problemas e intensifiquem a qualidade de vida dos seres. É, nesse panorama, que a pesquisa social crítica atua, ao propiciar melhor compreensão de como as sociedades agem e produzem efeitos tanto benéficos como maléficos, na perspectiva de alcançar, cada vez mais, a diminuição da ocorrência desse último (FAIRCLOUGH, 2003).

Apodero-me dessa perspectiva e estabeleço a ADC como campo basilar desta pesquisa, por ser abordagem teórico-metodológica que promove o estudo linguístico crítico em conexão com as ciências sociais e humanas. Desse modo, aproprio-me de uma teoria social do discurso que vai ao encontro das necessidades investigativas do mundo contemporâneo e que, ao mesmo tempo, pode ser instrumento para operar mudanças 
sociodiscursivas nas realidades. Baseado nisso, desenvolvo este estudo, o qual tem por propósito analisar como a líder política da nação brasileira atuou, por meio de seus discursos, para representar-se diante dos demais atores sociais.

Expressa Pedro (1998, p. 15) que a realização da ADC implica a não aceitação da neutralidade da investigação e do investigador, porque seus objetivos são traçados nos moldes políticos, sociais e culturais; a linguagem é tomada como forma de prática social e ideológica; as relações de poder, de dominação e de resistência, geradas por meio das instituições, contextualizam a interação entre os sujeitos. Devido a este panorama, as escolhas discursivas e textuais que fazemos são resultados da consciência que possuímos como falantes de uma língua particular e como sujeitos inseridos em convenções sociais institucionalizadas.

Em concordância com esses pressupostos, Fairclough (2001, p. 101) concebe profícua teórica e metodológica para realização da pesquisa discursiva social crítica, a qual é esboçada como a concepção tridimensional do discurso, reproduzida esquematicamente na figura abaixo.

Quadro 1 - A concepção tridimensional da ADC

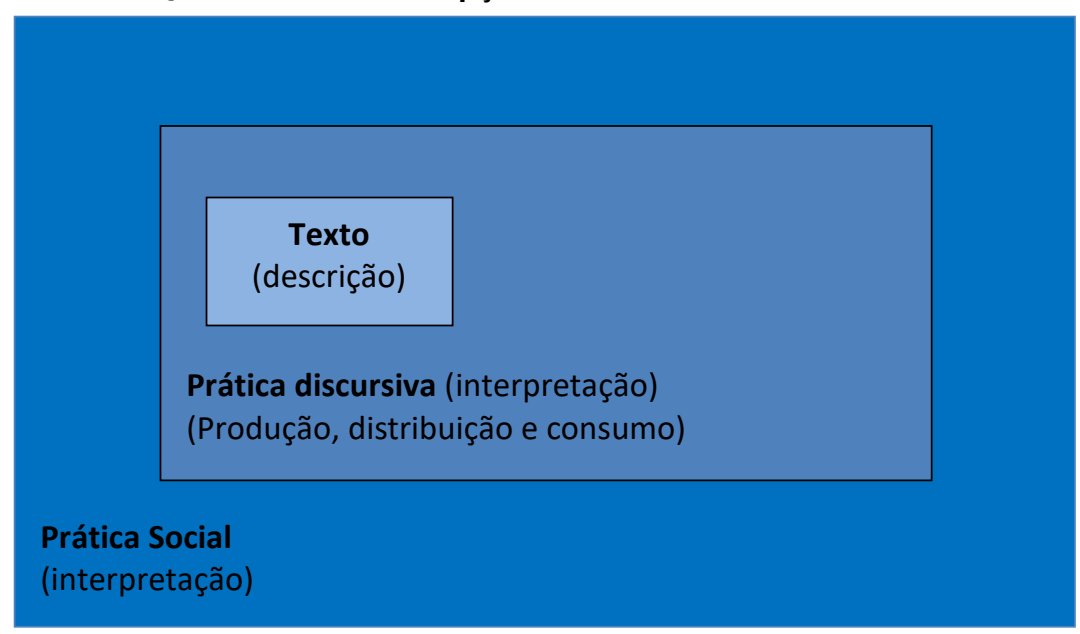

Fonte: elaboração do autor com base em Fairclough (2001).

Nesse caminho, Fairclough (2001) promove a união de três campos analíticos, discurso, prática discursiva e prática social, imprescindíveis para a análise de discurso. O discurso, de acordo com Fairclough (2001, p. 90-91), é compreendido como a utilização da linguagem, uma expressão de prática social. Isso revela que o discurso:

- configura-se como ação, maneira pela qual os indivíduos atuam sobre o mundo e sobre os outros, além de ser uma forma de representação; 
- é gerado no seio social;

- colabora para a construção de todos os âmbitos da estrutura social que, direta ou indiretamente, o transformam e o limitam, como também as relações, as identidades e as organizações que the são subjacentes;

- é uma prática que não se limita à representação, mas expressa a significação de tudo que existe, compondo e construindo o mundo em sentido.

Argumenta Fairclough (2001) que os meios de produção, de distribuição e de consumo dos textos são ações sociais que geram a prática discursiva. A essência desses processos é moldada de acordo com diferentes tipos discursivos sob influência de fatores sociais. Assim, os textos são gerados de modos particulares em conexão com contextos sociais específicos.

Com base nisso, a prática discursiva expressa-se linguisticamente em textos, os quais manifestam resultados mutáveis de base extradiscursiva, assim como discursiva. Esse fenômeno possibilita gerar mudanças nas atitudes, nas crenças ou nas práticas dos indivíduos (ibidem, p. 99-108).

Textos, conforme afirma Fairclough (2003, p. 10), expressam-se como qualquer exemplo de uso da linguagem. Nessa perspectiva, textos impressos e escritos, cópias de conversas e entrevistas (faladas), programas de televisão e páginas de internet são exemplos de produções textuais.

Dessa forma, a natureza do modo de produção da prática discursiva é considerada tanto tradicional como criativa. Devido a isso, ela coopera para expressar como a sociedade é, mas também para modificá-la. Assim, esse processo envolve modificações nas identidades e nas relações sociais, nos sistemas de crença e de conhecimento (FAIRCLOUGH, 2001, p. 92).

De acordo com Fairclough (2001, p. 94), a prática social se realiza com base em diversas orientações: econômica, política, cultural e ideológica. Porém, ele elucida que o enfoque maior, dessa obra, será o discurso enquanto forma de prática política e ideológica.

O discurso, na forma de prática política, tem função de instituir, de manter e de modificar as relações de poder e as entidades coletivas (classes, conjuntos, comunidades, grupos) com atuação de relações de poder entre si. 0 discurso, no modo de prática ideológica, constrói, naturaliza, sustenta e altera os significados do mundo de diferentes posições nas relações de poder. 
Sendo assim, Fairclough (2001, p. 94) aponta que essas duas dimensões de ação social possuem uma inter-relação. Em seu entendimento, a ideologia são significados concebidos nas relações de poder como fruto da atuação do poder e da luta pelo poder. Dessa forma, a prática política apresenta-se como categoria superior, na qual o discurso configura-se não somente como espaço de busca pelo poder, mas também como demarcador na luta de poder. Nesse processo, a prática discursiva mobiliza convenções que têm por função naturalizar relações de poder e ideologias específicas, além de tornar imperceptíveis as próprias convenções.

Consoante a essa visão, Fairclough (2001, p. 95) destaca que o discurso não possui valor fixo. Conforme diversos domínios ou espaços institucionais, tipos diferentes de discurso podem ser "investidos" política e ideologicamente de modos específicos. Sendo possível o "reinvestimento", quando modos de discurso são envolvidos de formas diferentes.

Aprofundando a compreensão sobre práticas sociais, Fairclough (2003, p. 28) elucida que elas podem ser depreendidas como formas de controlar a escolha de determinadas possibilidades estruturais e de excluir outras, e a apreensão de tais escolhas no decorrer do tempo, em dimensões específicas da vida social. Isso conduz ao entendimento da ligação que práticas sociais mantêm com eventos e estruturais sociais.

Por apresentar abordagens tão significativas na dimensão de análise que me aproprio para este trabalho, adotarei a concepção de Charaudeau (2015) sobre o discurso político, a qual apresentarei, sucintamente, na seção analítica. Dessa forma, como analista do discurso, acredito que devemos considerar e utilizar, de modo significativo, todas as possíveis contribuições de estudos na área da linguagem, independente de suas filiações ideológicas que limitam as interações entre os campos do saber.

Concluída, essa primeira parte, passemos à exposição da Teoria das Representações Sociais, porque, com base nesses apontamentos, balizarei a análise. 
Teoria das representações: caminho para compreender a maneira de viver dos atores sociais

A Teoria das Representações Sociais (TRS) é uma expressão sociológica da Psicologia Social, originada na Europa, a partir de um estudo realizado por Serge Moscovici em 1961. Como é próprio das ciências significativas, o autor ancorou-se em diversos teóricos da sociologia e da antropologia, especialmente em Durkheim, o que permite a TRS apontar o quanto o indivíduo é fruto da sociedade (FARR, 2013).

Guareschi e Jovchelovitch (2013) expressam importantes contribuições para o estudo da Teoria das Representações Sociais, ao relatar em que ela possui seu foco na relação entre o sujeito e o objeto. O sujeito, por meio de suas realizações e sua ligação com o objeto-mundo, cria tanto o mundo como a si próprio. Com isso, a centralidade da teoria se dá tanto nas atividades do sujeito como na realidade do mundo.

Com base nisso, a representação social, como fenômeno, envolve os campos cognitivos, por gerar conhecimentos sociais; afetivos, pois, quando os sujeitos se movem para compreender e expressar sentido ao mundo, realizam isso por meio de emoções, de sentimentos e de paixão; e sociais, porque as bases da cognição e do afeto estão situadas na realidade social, como também seus meios de produção encontram-se nas instituições, nos meios de comunicação e numa infinidade de lugares sociais. Quando as pessoas se pronunciam, articulam e se relacionam com outras a respeito do cotidiano ou sob influência de determinado espaço e práticas sociais, das crenças e da contribuição histórico-cultural de suas sociedades, é o momento em que as representações sociais são criadas (GUARESCHI; JOVCHELOVITCH, 2013). Nesse panorama, noto ligação com a proposta da $A D C$, a qual se interessa pela relação dos sujeitos e suas práticas no meio social, como também as mudanças e os efeitos que cada parte promove. Ratificando essa acepção, Moscovici, segundo Farr (2013, p. 44), assinala: “O indivíduo tanto é um agente de mudança na sociedade como é produto dessa sociedade.".

Segundo Minayo (2013, p. 92), a compreensão das representações realiza-se por meio da linguagem. As palavras são constituídas a partir de redes de fios ideológicos. Elas são espaços nos quais são confrontados diferentes interesses e, ao mesmo tempo, medeiam e recebem os efeitos das lutas. Dessa forma, há relação dialética com a realidade, todavia “não são a realidade, mas uma fresta iluminada: representam!”.

Compreende Jovchelovitch (2013, p. 66-77) que a representação é fenômeno psicossocial, como construções específicas da realidade social. É por meio das atividades 
e relações com os outros que se dá o nascimento das representações, o que proporciona tanto mediação entre sujeitos e mundo, quanto ressignificação do mundo por tais sujeitos.

$\mathrm{Na}$ visão de Minayo (2013), representações sociais realizam-se nas palavras, nos sentimentos e nos comportamentos e se institucionalizam. Com isso, podem e necessitam ser examinadas com base na compreensão e na atuação social. A mediação das representações é feita pela linguagem, que é aferida como modo de conhecimento e interação social, e, ainda, possui níveis diferenciados de percepção e nitidez em relação à realidade.

Em meio a esses entendimentos, esclareço que adoto o termo "atriz social", em vez de "ator social" ou "atora social”, para fazer referência à atuação social do sujeito feminino que, no caso deste estudo, é a presidenta da República Dilma Rousseff. Realizo esse esclarecimento porque na bibliografia aqui utilizada não há registro do uso desse termo para o sujeito feminino. No entanto, como esta pesquisa possui abordagem discursiva crítica, compreendo que devo me referir à atuação social do indivíduo em análise por meio de um substantivo que esteja ligado à sua classificação de gênero, ou seja, "atriz social”.

Baseado no exposto, sobre a Teoria da Representação Social, estabeleço conexão dessa perspectiva com a concepção da Representação dos Atores Sociais de van Leeuwen (1998), o qual produziu um inventário sociodiscursivo das formas pelas quais atores sociais podem ser representados, expressando a relevância sociológica e crítica de algumas categorias linguísticas.

Atores e atrizes sociais em cena: elenco das categorias de representação dos atores sociais

Alicerçado nessa compreensão, elenco as dez categorias de representação dos atores sociais de acordo com van Leeuwen (1998):

a) Exclusão: as representações podem operar incluindo ou excluindo atores sociais, de acordo com interesses e objetivos em relação aos leitores a quem se dirigem. Algumas exclusões “inocentes” ocorrem por conceber que leitores já conhecem determinada informação ou por entender que ela é irrelevante. Exclusões podem não 
deixar marcas, excluindo tanto atores sociais quanto suas atividades. Quando exclusões deixam marcas, opera-se: a supressão, pela qual não há qualquer menção aos atores sociais em questão; ou a colocação em segundo plano, quando atores sociais estão mencionados sutilmente numa parte do texto, por isso podem ser percebidos com pouca nitidez.

b) Distribuição de papéis: aos atores sociais, são entregues papéis para desempenharem nas representações. Isso implica quem é representado como agente (ator), e como paciente (finalidade) no discurso. Não há relação direta entre os papéis conferidos aos atores nas práticas sociais e os papéis gramaticais atribuídos a eles no texto. Assim, as representações podem redistribuir papéis e estruturar relações sociais entre sujeitos. Para realizar distribuição de papéis, recorre-se à circunstancialização, uso de circunstâncias preposicionais, e à possessivação, uso de pronomes possessivos para ativar ou passivar um ator social.

c) Genericização e especificação: expressam-se pela referência genérica ou específica. Atores sociais podem ser representados por meio de classes ou como indivíduos particulares e identificáveis.

d) Assimilação: é o modo como atores sociais podem ser referidos: como indivíduos (individualização), ou como grupos (assimilação). A individualização manifesta-se por meio da singularidade, e a assimilação se dá por meio da pluralidade. A assimilação é tipificada de dois modos. A agregação ocorre quando grupos de participantes são considerados dados estatísticos e, assim, auxiliam na sustentação de uma prática e na formação de consenso. A coletivização realiza-se quando um substantivo denota pessoas como grupos de grande extensão, na forma de nação ou comunidade, por exemplo.

e) Associação e dissociação: a associação configura-se em grupos de atores sociais que jamais são classificados no texto. A dissociação opera o processo inverso da associação, fragmentando os atores sociais.

f) Indeterminação e diferenciação: a indeterminação realiza-se quando atores sociais são representados como indivíduos ou grupos não particularizados e "anônimos". A diferenciação instaura-se quando a identidade dos atores sociais é, de alguma forma, especificada.

g) Nomeação e Categorização: a representação dos atores sociais pode se dá em relação a sua identidade única, dessa forma são nomeados; ou podem ser representados em termos de identidades e de funções que dividem com outros, consistindo na categorização. 
h) Funcionalização e identificação: são subdivisões da categorização. A funcionalização realiza-se quando atores sociais são mencionados de acordo com uma atividade ou função. Na identificação, atores sociais são definidos com base em algum nível de consolidação, por aquilo que são; e, também, baseado em categorias de classes.

i) Personalização e impersonalização: a personalização trata das representações que “personalizam” atores sociais, retratando-os como seres humanos. Ocorre, também, que atores sociais podem ser “impersonalizados”, representados por diferentes meios que os descaracterizam como humanos. Há dois tipos de impersonalização. Na abstração, atores sociais são representados com base em alguma qualidade que lhes é conferida pela representação. Na objetivação, atores sociais são representados com fundamento em um local ou uma coisa imediatamente associada a eles. Alguns tipos de objetivação são:

- espacialização: a representação é feita com base em um local ao qual os atores estão ligados num dado contexto;

- autonomização do enunciado: os atores são representados por meio de uma ligação aos seus enunciados;

- instrumentalização: “[...] os actores sociais são representados por meio de uma referência ao instrumento com o qual eles empreendem a atividade a que estão ligados”. (VAN LEEUWEN, 1998, p. 209); e

- somatização: a representação dos atores se dá com base numa referência a uma parte do seu corpo.

j) Sobredeterminação: acontece quando atores sociais são representados como participantes, ao mesmo tempo, de mais de uma prática social. Pode realizar-se de quatro formas: a) inversão: expressa-se quando atores sociais estão conectados a duas práticas que, de certa forma, são contrárias; b) simbolização: “[...] ocorre quando um actor social ou um grupo de actores sociais 'ficcionais' representam actores ou grupos em práticas sociais não-ficcionais." (VAN LEEUWEN, 1998, p. 212); c) conotação: consiste de única determinação corresponder a uma classificação ou funcionalização; d) destilação: propicia a sobre determinação por meio da junção da generalização com a abstração.

Finalizada essa apresentação das bases teóricas que alicerçam esse estudo, na próxima seção tratarei sobre os procedimentos metodológicos. 


\section{O caminho metodológico para desvelar a representação social}

A metodologia de natureza qualitativa foi escolhida para esta pesquisa, porque ela detém as principais características que a configuram como instrumento para investigação de questões linguísticas em conexão com aspectos da vida social.

De acordo com Bauer e Gaskell (2015), existem quatro dimensões que compõem a pesquisa social, as quais têm como função caracterizar o processo de investigação com base na união de elementos. As dimensões são: delineamento da pesquisa conforme princípios estratégicos; produção de dados; operação analítica dos dados e interesses de conhecimento. Os autores esboçam, ainda, que as quatro dimensões devem ser visualizadas como seleções relativamente independentes no percurso da pesquisa. Ao proceder à adoção pelo modo qualitativo ou quantitativo, deve-se considerar, num primeiro momento, que se trata da decisão sobre a forma de geração de dados e sobre os métodos analíticos e, num segundo momento, diz respeito à escolha do delineamento da pesquisa ou do interesse do conhecimento (ibidem, p. 20).

$\mathrm{Na}$ visão de Flick (2004, p. 20), os aspectos que regem a pesquisa qualitativa são: seleção apropriada de métodos e de teorias pertinentes ao estudo; reconhecimento e análise de distintas concepções; reflexões do pesquisador e diversidade de abordagens e métodos. Consonante isso, o autor afirma que esse tipo de pesquisa não está alicerçado em um conceito teórico e metodológico unificado. Ao contrário, inúmeras perspectivas constroem as discussões e a prática da investigação. A pesquisa pode estruturar-se a partir de pontos de vista subjetivos; pelo estudo da elaboração e do percurso das interações; e pelo trabalho em refazer as estruturas da dimensão social e o significado que emana das práticas (ibidem.).

Esse levantamento teve a finalidade de explicitar os motivos da escolha do método qualitativo de análise.

\section{A coleta de dados}

Conforme o percurso descrito abaixo, a coleta de dados foi realizada:

1. Durante o ano de 2015 até o mês de maio do ano de 2016 foram observadas as postagens dos discursos oficiais da chefe de Estado, de forma integral e transcritos textualmente, no site oficial do Palácio do Planalto e suas divulgações pela mídia social 
Facebook. A observação, por meio dessa mídia social, foi feita na perspectiva de ser instrumento que pudesse transmitir, em alguma medida, o nível de receptividade e de difusão das produções discursivas presidenciais junto à população.

2. A princípio, foram coletados treze discursos baseados nos seguintes critérios: maior ocorrência da representação social da líder política e tratamento das temáticas: educação, saúde, segurança, política e economia.

3. Desse total, selecionei os três discursos mais significativos para compor o corpus de pesquisa, por satisfazerem aqueles requisitos estabelecidos: maior realização de representação social da presidenta em conexão com as temáticas da vida social dos brasileiros. Nesse sentido, saliento que os discursos oficiais de 2016 não foram selecionados porque não atenderam a tais condições. Os discursos, desse período, assumiram determinadas funções sócio-políticas que não correspondiam aos objetivos deste estudo.

Esse foi o modo como a coleta de dados da minha dissertação de mestrado foi realizada. Todavia, como o espaço deste artigo acadêmico é limitado e os discursos oficiais são extensos, apresentarei a análise de um desses discursos da governante federal no ano de 2015.

Depois de detalhar o método analítico, seguem as categorias de análise. 0 discurso selecionado foi examinado à luz da teoria da ADC, conforme Fairclough (2001), e por meio do elenco das categorias da Representação dos Atores Sociais de van Leeuwen (1998). Dessa forma, será possível compreender de que modo a presidenta da república representou-se por meio de seu discurso oficial e qual implicação essa ação promoveu no meio social. A seguir, o processo analítico será iniciado.

\section{Em cena: a representação da atriz social presidenta da república}

Antes de iniciar o processo analítico, o discurso oficial da presidenta da República, selecionado para esta investigação, será apresentado em sua forma completa. 
Mensagem ${ }^{2}$ da Presidenta da República, Dilma Rousseff, por ocasião do Dia da Independência. Publicado no site do Palácio do Planalto, em 07/09/2015, às $16 \mathrm{~h} 24$.

Meus queridos brasileiros e brasileiras, eu gostaria de conversar com vocês hoje, 7 de setembro, que é a data mais importante para o Brasil. Hoje é também o momento certo para refletir, falar sobre a preocupação de todos nós quanto ao presente e ao futuro do país.

É verdade que atravessamos uma fase de dificuldades, enfrentamos problemas e desafios. Sei que é minha responsabilidade apresentar caminhos e soluções para fazer a travessia que deve ser feita.

As dificuldades e os desafios resultam de um longo período em que o governo entendeu que deveria gastar o que fosse preciso para garantir um emprego e a renda do trabalhador, a continuidade dos investimentos e dos programas sociais. Agora temos de reavaliar todas essas medidas e reduzir as que devem ser reduzidas.

Nossos problemas também vieram lá de fora e ninguém que seja honesto pode negar isso. Está visível que a situação em muitas partes do mundo voltou a se agravar, atingindo agora os países emergentes. Países importantes, parceiros do Brasil, tiveram seu crescimento reduzido e foram atingidos pela crise internacional. 0 mundo, além disso, enfrenta tragédias de natureza humanitária como mostra a situação chocante dos refugiados que morrem nas praias europeias ao tentar buscar refúgio da guerra.

A imagem do menino AylanKurdi de apenas três anos comoveu todos nós e deixou um grande desafio para o mundo. Nós, o Brasil, somos uma nação que foi formada por povos das mais diversas origens que aqui vivemos em paz, mesmo em momentos de dificuldades, de crise, como os que estamos passando, teremos os nossos braços abertos para acolher os refugiados.

Aproveito o dia de hoje para reiterar a disposição do governo de receber aqueles, que expulsos de suas pátrias, para que queiram vir, viver, trabalhar e contribuir para a prosperidade e a paz do Brasil. As dificuldades, insisto, são nossas e são superáveis. $O$ que eu quero dizer com toda franqueza é que estamos enfrentando os desafios, estas dificuldades e que vamos fazer essa travessia.

Se cometermos erros, e isso é possível, vamos superá-los e seguir em frente. Quero dizer a vocês alguns remédios para essa situação, é verdade são amargos, mas são indispensáveis.

As medidas que estamos adotando são necessárias para botar a casa em ordem, reduzira inflação, por exemplo, nos fortalecer diante do mundo e conduzir, o mais breve possível, o Brasil à retomada do crescimento. Podemos e queremos ser exemplo para o mundo, exemplo de crescimento econômico e valorização das pessoas.

O esforço de todos nós é que vai nos levar a superar esse momento. Eu sei disso. Também sei que a união em torno dos interesses de nosso país e de nosso povo é a força capaz de nos conduzir nessa travessia. Devemos nessa hora estar acima das diferenças menores, colocando em segundo plano os interesses individuais ou partidários.

Me sinto preparada para conduzir o Brasil no caminho de um novo ciclo de

\footnotetext{
${ }^{2}$ Discurso disponível em:<https://www2.planalto.gov.br/acompanhe-o-planalto/discursos/discursos-dapresidenta/mensagem-da-presidenta-da-republica-dilma-rousseff-por-ocasiao-do-dia-daindependencia>.Acesso em: 20 nov. 2015.
} 
crescimento, ampliando as oportunidades para o nosso povo subir na vida com mais e melhores empregos. Nós queremos o país com a inflação sobre controle, juros decrescentes, renda e salários em alta.

Eu posso garantir a vocês que nenhuma dificuldade me fará abrir mão da alma e do caráter do meu governo. A alma e o caráter do meu governo é assegurar neste país de grande diversidade oportunidades iguais para nossa população, sem recuos, sem retrocessos.

Nós fomos capazes de tirar milhões de pessoas da miséria e elevar outros milhões aos padrões de consumo das classes médias. Vamos voltar a crescer para avançar ainda mais nesse caminho, construindo um Brasil de trabalhadores e empreendedores, de estudantes, de cientistas, da agricultura, do comércio, da indústria dos serviços, mas sabemos ainda falta muito para fazer e por isso precisamos voltar a crescer. Crescer para levar, por exemplo, a educação de qualidade para todo nosso povo da creche à pós-graduação.

Temos experiências vencedoras e hoje quero contar uma grande vitória, acabamos de ganhar o primeiro lugar na Olimpíada Mundial do Conhecimento Técnico, que contou com a participação de mais de 59 países. Pesos pesados em formação profissional, como, por exemplo, a Alemanha, a Coréia do Sul, o Japão, a França.

A boa notícia é que $84 \%$ dos vitoriosos tinham feito ou estavam fazendo o Pronatec, que é uma parceria entre o governo e o Senai que dá bolsas para formação técnica. Gostaria de destacar que a família de um dos medalhistas de ouro recebia também o Bolsa Família, o que lhe ajudou a participar da olimpíada. Queridos brasileiros, queridas brasileiras, o Dia da Independência deve ser momento de encontro do Brasil consigo mesmo. Uma celebração e um tributo que prestamos aos heróis que lutaram para um Brasil forte, livre e independente. É neste dia que devemos pensar qual país queremos para nós e para nossos filhos e netos. É neste dia que honramos os heróis da independência, que homenageamos todos os brasileiros que lutaram e deram suas vidas para que nosso país ficasse sempre livre da opressão. É neste dia que reafirmamos aquilo que uma nação ou um povo tem de melhor, a capacidade de lutar e a capacidade de conviver com a diversidade. Tolerante, em face às diferenças, respeitoso na defesa das idéias, sobretudo, firme na defesa da maior conquista alcançada e pela qual devemos zelar permanentemente, a democracia e a adoção do voto popular como método único e legítimo de eleger nossos governantes e representantes.

A independência, queridos brasileiros e brasileiras, acontece todos os dias no país, nas nossas casas, nas nossas famílias, dentro de cada um de nós. É a força de nossa autoestima como povo, e a certeza que os brasileiros são aquilo que o Brasil tem de melhor, com o nosso trabalho, com a nossa união, com o nosso esforço para manter nossas famílias, criar nossos filhos e netos e com a alegria que passamos pelos bons momentos e com a coragem com que enfrentamos os momentos ruins.

Somos todos lutadores pela independência do Brasil. Hoje, mais do que nunca, somos todos Brasil.

Muito Obrigada 
Eu e nós: somos um. Individualização $x$ assimilação e a distribuição de papéis para 0 protagonismo presidencial

O processo analítico será regido pelo exame discursivo dos modos representacionais assimilação e distribuição de papéis, propostos por van Leeuwen (1998), os quais foram alicerces para a presidenta da República construir sua representação social.

Esse discurso presidencial foi produzido em forma de mensagem comemorativa do Dia da Independência do Brasil: data que manifesta o sentimento nacionalista e o amor à pátria. Por isso, constitui frutífero evento social para que a líder política da nação construa sua representação social e, assim, aborde questões importantes ligadas à manutenção da sociedade. Com base nisso, Dilma Rousseff utilizou esse discurso para apresentar as ações e as medidas do governo federal em relação à principal questão do clamor social até aquele momento: o contexto de crise.

0 contexto de crise, ao qual me refiro neste estudo, esteve presente e influenciou profundamente a prática discursiva, a atuação e a representação de Dilma Rousseff como representante do governo federal, especialmente em 2015, quando foram coletados os discursos que compõem o corpus desta pesquisa. A crise que abate o Brasil é um tema complexo e controverso, pois, ao ser instaurada, atingiu as principais instâncias relacionadas à regulação social: política e economia, o que causou efeitos adversos, também, na saúde, na educação, na segurança entre outros.

Grande parcela de especialistas políticos e financeiros, por meio da mídia informativa ${ }^{3}$, pontua que a crise estabeleceu-se no ano de 2014: quando a situação financeira e fiscal agravou-se; a presidenta encontrava-se com baixa popularidade; muitos de seus aliados deixaram de apoiá-la e, assim, muitos projetos e medidas não foram aprovados na Câmara dos Deputados. Junto a isso, ocorreu o início da maior operação nacional de investigação sobre corrupção no país, a Lava Jato, que disseminou pânico numa parcela de políticos e de empresários envolvidos em atos criminosos contra bens públicos, o que afetou o trabalho de grandes empresas; houve recorrentes manifestações da população insatisfeita com a alta dos preços, dos juros e da taxa de desemprego; com o aumento da inflação, houve desequilíbrio nas contas públicas e, consequentemente, nas dos cidadãos.

\footnotetext{
${ }^{3}$ Fonte: disponível em: <www.oglobo.globo.com/brasil/linha-do-tempo-entenda-crise-que-culminou-noimpeachment-20015867>; <www.epoca.globo.com/ideias/noticia/2016/04/como-o-brasil-entrou-sozinhona-pior-crise-da-historia.html $>$ e <www1.folha.uol.com.br/poder/2016/08/1808784-senado-cassamandato-de-dilma-congresso-dara-posse-efetiva-a-temer.shtml>. Acesso em: 15 de set. 2016.
} 
Depois do esboço das questões sociais e do cenário no qual a presidenta da República do Brasil encontrava-se emergida, prossigo à análise de seus modos representacionais.

Meus queridos brasileiros e brasileiras, eu gostaria de conversar com vocês hoje, 7 de
setembro, que é a data mais importante para o Brasil. Hoje é também o momento certo
para refletir, falar sobre a preocupação de todos nós quanto ao presente e ao futuro do
país.
É verdade que atravessamos uma fase de dificuldades, enfrentamos problemas e
desafios. Sei que é minha responsabilidade apresentar caminhos e soluções para fazer
a travessia que deve ser feita [...].

Consoante Fairclough (2001), o discurso é prática que não se limita à representação, mas expressa a significação de tudo que existe, compondo e construindo o mundo em sentido. É ancorada nesse recurso que Dilma Rousseff, naquele momento, como ocupante do mais notório papel político da realidade brasileira, inicia seu discurso e constrói sua representação social. Assim, nesse fragmento, ao iniciar o discurso, ela individualizou-se, por meio da primeira pessoa do singular (eu), a fim de chamar a atenção dos cidadãos para o fato de que ela está disponível naquele momento, pessoalmente, para conversar e tratar de assuntos que ansiavam por respostas e soluções.

Porém, imediatamente, ela compartilha sua responsabilidade e insere todos os cidadãos em sua prática de governo, pelo uso da assimilação por coletivização(nós). É interessante notar que a governante invocou em seu discurso a força social do evento Independência da República do Brasil e, consequentemente, teceu todo seu texto baseada nas possibilidades dos efeitos sociais que tal evento propicia.

Dilma Rousseff inicia seu discurso político destacando o aspecto principal de seu papel: propor e gestar as ações e os meios das instâncias da vida social dos brasileiros. Dessa maneira, ela consolida seu papel de agente e abre caminho para que os espectadores aceitem a sua atuação. No fragmento $\dot{E}$ verdade que atravessamos uma fase de dificuldades, enfrentamos problemas e desafios. Sei que é minha responsabilidade apresentar caminhos e soluções para fazer a travessia que deve ser feita, a presidenta dá prosseguimento ao modo de representação eleito como mais significativo, para ela, enquanto governante inserida em momento de crise, a coletivização.

Esse modo é construído pelos verbos conjugados na primeira pessoa do plural, mas sem a marcação do sujeito. Tal representação ocorreu porque a presidenta já inseriu os atores brasileiros em sua prática “Meus queridos brasileiros e brasileiras...", de modo que, 
agora, é natural a participação deles. A inclusão da presidenta, nesse momento, visa suscitar o sentimento de unidade e de companheirismo, já que "atravessamos" e "enfrentamos" expressa que ela sempre esteve presente com todos no enfrentamento das adversidades, assim como nesse atual momento.

As dificuldades e os desafios resultam de um longo período em que o governo entendeu que deveria gastar o que fosse preciso para garantir um emprego e a renda do trabalhador, a continuidade dos investimentos e dos programas sociais. Agora temos de reavaliar todas essas medidas e reduzir as que devem ser reduzidas. Nossos problemas também vieram lá de fora e ninguém que seja honesto pode negar isso.

Há representação por individualização em “o governo entendeu”, quando a presidenta refere-se ao governo exercido por sua pessoa, ressaltando as ações benéficas que ela praticou para manter o bem-estar social. Todavia, o termo "o governo" é, também, coletivo porque representa o grupo de pessoas que auxiliam Dilma Rousseff em sua gestão. É um modo de coletivizar seu papel social e, consequentemente, suas responsabilidades, já que ela estava expressando justificativas de problemas latentes da sociedade.

Num segundo momento, a líder política volta a promover sua inclusão no grande grupo, formado por todos participantes de seu governo e pelo povo que recebeu a identidade social de "honesto". Por isso, os brasileiros devem entender e não questionar o porquê do quadro político daquele momento.

A imagem do menino AylanKurdi ${ }^{4}$ de apenas três anos comoveu todos nós e deixou um grande desafio para o mundo. Nós, o Brasil, somos uma nação que foi formada por povos das mais diversas origens que aqui vivemos em paz, mesmo em momentos de dificuldades, de crise, como os que estamos passando, teremos os nossos braços abertos para acolher os refugiados.

Segundo Fairclough (2003), eventos sociais são resultados não só das estruturas linguísticas e dos seus modos de organização e de controle social, mas se portam como efeitos de outras estruturas e práticas sociais em todas suas formas. Com essa natureza, eventos sociais possuem capacidade de influenciar a geração de novos textos, imprimindo seus efeitos sociais.

\footnotetext{
${ }^{4}$ A menção que Dilma Rousseff faz nesse momento diz respeito à história de AylanKurdi, um menino sírio de três anos que apareceu afogado numa praia da Turquia no dia 2 de setembro de 2015. As fotos em que aparece o seu corpo falecido na costa turca e as de um agente da polícia transportando seu cadáver tiveram grande repercussão mundial. Tal evento suscitou inúmeras manifestações e debates sobre a problemática dos refugiados de guerra.
} 
Assim, ao evocar para seu discurso o evento de refugiados de guerra que deixam seus países em busca de lugar seguro, Dilma Rousseff em “comoveu todos nós” constrói sua imagem de líder humana e preocupada com as questões sociais que afligem o povo e o mundo. No mesmo instante, por estar representada com os brasileiros num mesmo grupo, ela mobiliza o entendimento de que cada participante deve ser tolerante, aceitar sua atuação enquanto governo e ser um cooperador para mudar essa realidade, como se vê em "de crise, como os que estamos passando, teremos os nossos braços abertos para acolher...". Tal construção pauta-se por aquilo que Charaudeau (2015) propõe: “o discurso político é, por excelência, o lugar de um jogo de máscaras. Toda palavra pronunciada no campo político deve ser tomada ao mesmo tempo pelo que ela diz e não diz".

As dificuldades, insisto, são nossas e são superáveis. 0 que eu quero dizer com toda franqueza é que estamos enfrentando os desafios, estas dificuldades e que vamos fazer essa travessia.

Se cometermos erros, e isso é possível, vamos superá-los e seguir em frente. Quero dizer a vocês alguns remédios para essa situação, é verdade são amargos, mas são indispensáveis.

As medidas que estamos adotando são necessárias para botar a casa em ordem, reduzir a inflação, por exemplo, nos fortalecer diante do mundo e conduzir, o mais breve possível, o Brasil à retomada do crescimento. Podemos e queremos ser exemplo para o mundo, exemplo de crescimento econômico e valorização das pessoas.

Nesses dois fragmentos, por um lado, a representação da presidenta é por individualização para expressar que ela é a atriz política dotada de sinceridade e de caráter, a qual possui visão e aptidão para relatar fielmente a realidade e os possíveis progressos que pode vir a ocorrer.

Dilma representa-se, na maior parte, por assimilação por coletivização, com propósito de desviar sua imagem de única responsável pelo contexto de crise que alcança todas as instâncias da vida social dos brasileiros. Mesmo quando afirma que proporá soluções, ela continua com igual modo representacional, tanto para desviar a culpa e a cobrança de soluções por parte da população, quanto para transportar os demais sujeitos para sua prática governamental.

A representação como agente encarnada na figura de salvadora "[..] O que eu quero dizer com toda franqueza é que estamos enfrentando os desafios, estas dificuldades $e$ que vamos fazer essa travessia. [...]Quero dizer a vocês alguns remédios para essa situação, é verdade são amargos, mas são indispensáveis."implica demonstrar qualidades como 
sinceridade, domínio e aptidão, para que seu papel social alcance significância e sua representação cause os efeitos esperados.

0 esforço de todos nós é que vai nos levar a superar esse momento. Eu sei disso. Também sei que a união em torno dos interesses de nosso país e de nosso povo é a força capaz de nos conduzir nessa travessia. Devemos nessa hora estar acima das diferenças menores, colocando em segundo plano os interesses individuais ou partidários.

A chefe de Estado prossegue sua representação, como participante do grupo composto por todos outros grupos sociais, por estar diante de cenário repleto de conflitos e oposições, o qual requer posicionamentos efetivos referentes a seu papel social. Ela individualiza-se apenas para reafirmar sua presença e seu papel social como liderança.

Ao dividir, pelo menos no campo do imaginário, a função de governo com o povo, como em “[...] O esforço de todos nós é que vai nos levar a superar esse momento." $e$ "[...] Devemos nessa hora estar acima das diferenças menores", Dilma anseia construir com essa representação aquilo que Charaudeau (2015) assinala como sistema de pensamento, o qual é efeito de ação discursiva que visa alicerçar um ideal político baseado em princípios que se portam como norteadores para a constituição de opiniões e posicionamentos, e, assim, originam-se as filiações ideológicas.

Me sinto preparada para conduzir o Brasil no caminho de um novo ciclo de crescimento, ampliando as oportunidades para o nosso povo subir na vida com mais e melhores empregos. Nós que remos o país com a inflação sobre controle, juros decrescentes, renda e salários em alta. [..] Eu posso garantir a vocês que nenhuma dificuldade me fará abrir mão da alma e do caráter do meu governo. A alma e o caráter do meu governo é assegurar neste país de grande diversidade oportunidades iguais para nossa população, sem recuos, sem retrocessos.

Nos trechos "[...] me sinto preparada..." “[...] Eu posso garantir a vocês..." “[...] me fará abrir mão da alma...", a atriz social individualiza-se somente para construir imagem de controle, de força e de quem sabe para onde está conduzindo a nação. Assim, sua imagem pode ser concebida como porto seguro e como figura salvadora. Outro possível entendimento que apresento é que essas construções representacionais da presidenta esboçam uma estratégia recorrente: por meio da coletivização, reforçado pelo uso do “nós”, Dilma torna-se parte do povo brasileiro a tal ponto que ela personifica o sentir e o querer do povo. Nesse sentido, ela e a população possuem os mesmos anseios e sonhos. 
Uma concepção que esboça o motivo da representação predominante da presidenta ora como sujeito ora como pertencente ao grupo da população, assim como exemplificado nesse excerto, está descrita nas palavras de Moscovici (2013), que declara que representações sociais constituem-se racionais, não pelo seu viés social, mas porque são coletivas. E é no espaço das tensões entre o individual e social que os sujeitos constroem suas representações.

Relata Minayo (2013, p. 90) que representações sociais têm núcleos positivos de mudança e de resistência na forma de compreender a realidade. Por isso, devem ser analisadas criticamente, pois elas expressam situações reais da vida. "Na verdade, a realidade vivida é também representada e através dela os atores sociais se movem, constroem sua vida e explicam-na mediante seu estoque de conhecimentos." Baseado nessa concepção, percebo que a atriz social Dilma Rousseff possui determinada leitura da realidade sociopolítica brasileira e, a partir disso, ela constrói um papel de agente ativo e capaz para a condução da nação, o que é ratificado pelas declarações: "[...] Me sinto preparada para conduzir o Brasil..." e “[...] Eu posso garantir a vocês...”.

Todavia, há certa variação no grau de certeza que a presidenta possui sobre seu preparo, o que expressa a noção de que, em relação à resolução de determinadas questões ela está apta para resolver “[...] Eu posso garantir a vocês que nenhuma dificuldade me fará abrir mão da alma e do caráter do meu governo..."; porém, em relação às outras, ela ainda está em fase de preparação “[...]Me sinto preparada para conduzir o Brasil no caminho de um novo ciclo de crescimento...". Nesse ponto, é importante observar o sentido estabelecido pelas formas “posso garantir", que expressa total certeza, em oposição à forma “Me sinto", que não apresenta a mesma força enunciativa: "sentir-se preparada" não necessariamente significa "estar preparada".

Ela utiliza seu estoque de conhecimentos para construir representação que transmita imagem de controle e de discernimento, mobilizando a noção de figura salvadora, como em “[...] A alma e o caráter do meu governo é assegurar neste país...”.

Nós fomos capazes de tirar milhões de pessoas da miséria e elevar outros milhões aos padrões de consumo das classes médias. Vamos voltar a crescer para avançar ainda mais nesse caminho, construindo um Brasil de trabalhadores e empreendedores [...]mas sabemos ainda falta muito para fazer e por isso precisamos voltar a crescer. Crescer para levar, por exemplo, a educação de qualidade para todo nosso povo da creche à pós-graduação. 
A presidenta traz para sua representação, no modo assimilação por coletivização, a presença dos cidadãos, a imagem de seu antecessor e todo seu projeto de governo “[..]Nós fomos capazes de tirar milhões de pessoas da miséria e elevar outros milhões aos padrões de consumo das classes médias....". Dilma faz essa referência porque acredita que as conquistas obtidas pelo governo anterior, o qual é seu aliado, poderão fortalecer sua representação como governo federal.

Segundo Charaudeau (2015), um dos modos de formação do discurso político é o ato de comunicação, o qual diz respeito mais aos atores sociais que estão na encenação da comunicação política, cujo propósito está no convencimento das opiniões com objetivo de obter aprovações, rejeições ou consensos.

Para isso, opera-se a sedução, ou seja, os sujeitos são persuadidos a aceitar e a acreditar em determinada construção de sentido defendido pelo político, assim como se deu no discurso de Dilma Rousseff. Como ela faz parte da população, busca transmitir a noção de que o governo sabe bem as reais necessidades população e, devido a isso, executará tudo que é possível para promover o bem comum. Como exemplo, foi mencionada a questão da educação, já que é senso comum que político “bom” é aquele que se preocupa com educação.

É neste dia que honramos os heróis da independência, que homenageamos todos os brasileiros que lutaram e deram suas vidas para que nosso país ficasse sempre livre da opressão. É neste dia que reafirmamos aquilo que uma nação ou um povo tem de melhor, a capacidade de lutar e a capacidade de conviver com a diversidade. [...] sobretudo, firme na defesa da maior conquista alcançada e pela qual devemos zelar permanentemente, a democracia e a adoção do voto popular como método único e legítimo de eleger nossos governantes e representantes.

Todavia discursar para toda uma nação, tratando de temas que carecem de extremos cuidados, envolve procedimentos complexos. Por isso, Dilma construiu sua representação não apenas baseada na força de um evento importante para o Brasil, mas de um evento que gerou a criação de uma estrutura social política, a República, a qual possibilita que ela atue como líder política da nação que luta, nos dias atuais, para que novamente o povo fique livre das adversidades ([...]É neste dia que honramos os heróis da independência, que homenageamos todos os brasileiros que lutaram e deram suas vidas para que nosso país ficasse sempre (ivre da opressão.).

A respeito disso, Fairclough (2003, p. 29) pontua que estruturas consistem em entidades abstratas, assim como uma estrutura econômica ou política, uma classe social. Assim, estruturas sociais configuram-se como forma potencial, como junção de 
possibilidades. É, graças a isso, que ela está ali, como representante eleita, "convocando" a todos para portarem-se como aqueles que um dia lutaram e possibilitaram a mudança de realidade do Brasil ([...]É neste dia que reafirmamos aquilo que uma nação ou um povo tem de melhor, a capacidade de lutar e a capacidade de conviver com a diversidade.).

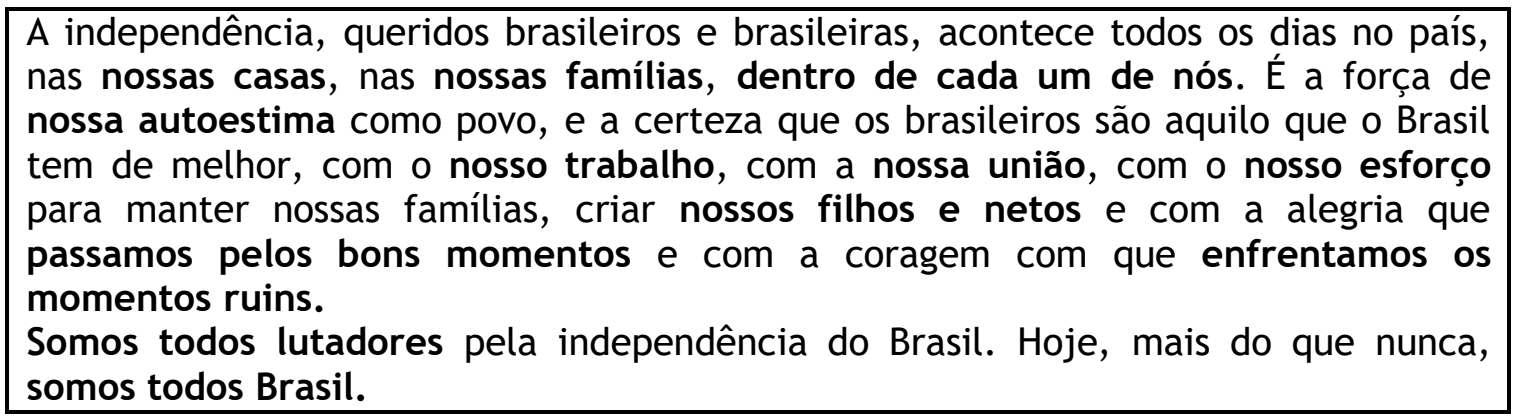

A presidenta encerra esse discurso sem mais individualizar-se, não há mais um “eu”, apenas “nós” “[...] nossas casas, nas nossas famílias, dentro de cada um de nós. É a força de nossa autoestima como povo...". Nesse momento, ela está representada, pela coletivização, como parte indissociável do povo, eles são um, por meio da mobilização da noção de unidade. Com isso, houve expansão de uma das suas principais estratégias: o pessoal foi apagado pelo coletivo que assume papel central no discurso. Assim, há um caminho aberto para que suas ideias e suas propostas sejam aceitas e disseminadas como um bem-comum.

A chefe de Estado, constantemente, trabalha para gerar no povo o sentimento de que ela pertence a ele e, com isso, visa tocar-lhe as emoções e transmitir a noção de onisciência, ou seja, ela é um membro tão íntima que conhece cada necessidade e desejo da população. Esse processo confirma-se pelo uso dos termos representacionais: “nossas casas", “nas nossas famílias" e "nossos filhos e netos”.

Com base no fortalecimento e na exaltação da identidade nacional, foi estabelecida única identidade social para os brasileiros, consolidando, assim, a ideia de força, de capacidade e de conquista, mesmo diante de um contexto de crise em todas as instâncias sociais "[...] e com a alegria que passamos pelos bons momentos e com a coragem com que enfrentamos os momentos ruins.

Somos todos lutadores pela independência do Brasil. Hoje, mais do que nunca, somos todos Brasil.".

A motivação para tal formação representacional ampara-se no que Guareschi e Jovchelovitch (2013) asseveram: 
quando sujeitos sociais empenham-se em entender e dar sentido ao mundo, eles também o fazem com emoção, com sentimento e com paixão. [...] Tanto a cognição como os afetos que estão presentes nas representações sociais encontram a sua base na realidade social (GUARESCHI; JOVCHELOVITCH, 2013, p. 19).

Utilizando como bases a emoção, os sentimentos de coragem e de certeza e, em certa medida, a paixão, Dilma Rousseff construiu um de seus modos representacionais mais expressivos do ano de 2015. Essa representação social nasceu por meio de um discurso oficial produzido sob forte influência do evento social, Dia da Independência, e da cobrança extrema da sociedade por posicionamento e medidas efetivas da presidenta em relação ao contexto de crise já latente naquele momento.

Por isso, podemos ver a presidenta mobilizando, discursivamente, várias estratégias que visaram tocar e persuadir seu público a respeito de sua imagem como membro ativa e compadecedora do grande grupo de brasileiros e, por outro lado, como a "heroína" que conduzirá todos às conquistas de melhorias permanentes.

Aqui, finalizo o processo analítico do modo representacional da chefe de Estado. No próximo momento, expressarei algumas compreensões e considerações sobre esse estudo. 
Alcançando entendimentos, descobrindo caminhos... a representação social da presidenta da república Dilma Rousseff

Após o processo analítico, compreendi que o modo de representação social da presidenta da República do Brasil configurou-se do seguinte modo:

Figura 2: Modo da representação social da Presidenta da República Dilma Rousseff no ano de 2015

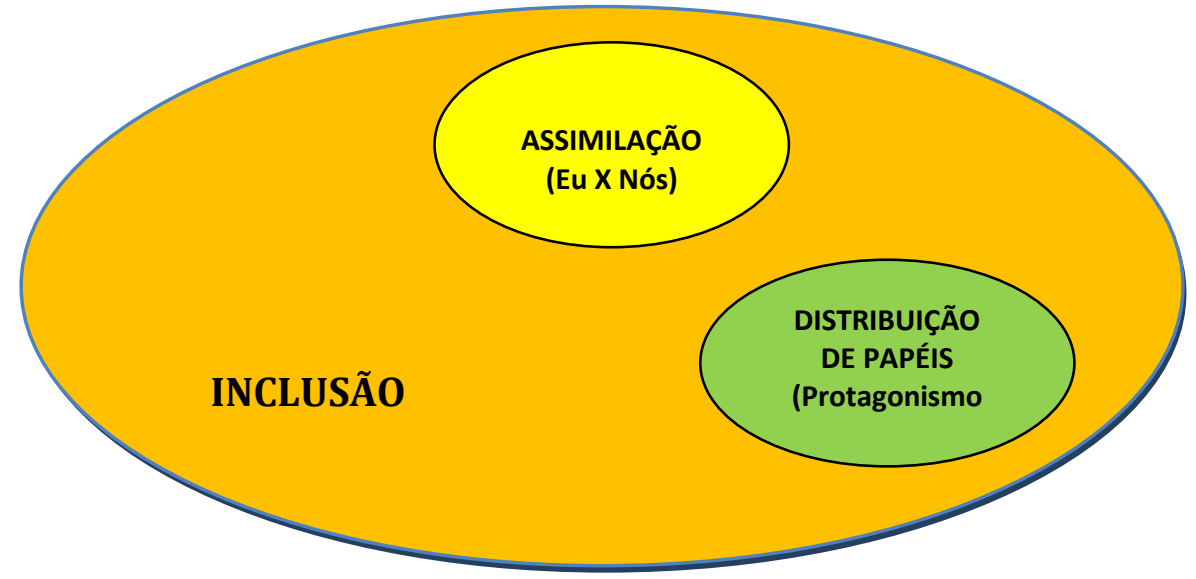

Fonte: elaboração do autor.

Em consonância com essa figuração representacional, apresentarei algumas conclusões a que cheguei. Primeiro, os discursos analisados, por serem a transcrição literal dos pronunciamentos oficiais da chefe de Estado, são extensos, o que favorece a instauração de redundância, e não possuem única linha argumentativa nem tratamento exclusivo de uma temática.

Alicerçado na concepção da ADC de Fairclough (2001), sobre as propriedades de construção representacional que o discurso possui; nos pressupostos da Teoria da Representação Social de Guareschi e Jovchelovitch (2013) e de Minayo (2013); e no elenco dos modos pelos quais os atores sociais podem representar-se, conforme van Leeuwen (1998), constatei que a principal forma como Dilma Rousseff constrói sua representação é promovendo sua Inclusão como membro efetivo de um corpo social composto por todos os brasileiros.

Para isso, como primeiro passo, a presidenta mobiliza a construção representacional Eu X Nós. Dessa maneira, na maior parte do seu discurso, ela representa-se por Assimilação, ou seja, apresenta-se como parte indissociável do grande grupo formado por todos os brasileiros. Quando é preciso ressaltar suas qualidades, a 
relevância de seu(s) papel(is), consolidar sua identidade pessoal, política ou social, Dilma Rousseff constrói representações com base na primeira pessoal do singular eu, colocando-se em evidencia nesses momentos. Porém, logo retoma sua interpretação como participante do grupo dos cidadãos brasileiros.

Ao promover constante ação representativa fundamentada na noção do nós, por meio do modo assimilação por coletivização, a governante federal, ao longo do percurso discursivo, cria um grande corpo social, composto por todos(as) brasileiros(as), no qual quem exerce a função de cabeça, de liderança é a presidenta da República. Assim, ela se mostra como líder política responsável por: direcionar os passos da população, oferecer respostas e justificativas para as questões conflitantes do povo, e propor medidas e mudanças necessárias para o estabelecimento de um cenário social de equilíbrio e de vitórias alcançadas.

Todavia, nesse mesmo caminho, a chefe de governo, por ser a comandante desse corpo social - a nação brasileira -, gera o entendimento nos cidadãos de que eles são os principais responsáveis pelo "fazer social". Dessa forma, para que se alcance o bom desempenho dos setores da sociedade, se consiga a melhoria e o progresso dos elementos que formam a vida dos brasileiros, é necessário que eles aceitem o que a chefe de governo propõe e atuem conforme suas diretrizes.

Como segundo passo para promover a Inclusão, logo depois da ação representacional por Assimilação, a presidenta utiliza a Distribuição de papéis para esboçar as posições e as figurações que cada membro da sociedade receberá. Nesse sentido, na maior parte do percurso investigativo, Dilma Rousseff representou-se como agente, num papel de protagonista da cena política do Brasil, numa posição ativa devido à sua representação de líder capacitada e humana, construída num primeiro momento.

Em conexão com esse processo, podemos pensar que, ao mesmo tempo em que Dilma representa os brasileiros nos papéis de, também, responsáveis pelo bom exercício da prática de governança, a eles são conferidos papéis passivos, por portarem-se como a finalidade, o alvo para o qual a representação da governante federal destina-se.

Com essa explanação, volto à questão inicial desta pesquisa:de que modo a presidenta da República do Brasil, Dilma Rousseff, por meio de seu discurso oficial, construiu sua representação social no ano de 2015?

A presidenta da República, Dilma Rousseff, utilizou seus discursos oficiais para construir sua representação social com dupla face, baseada no modo Inclusão. Assim, na primeira face, ela é membro fundamental do corpo social formado pela população brasileira, no qual exerce função de liderança, por meio da Assimilação por 
coletivização. Na segunda face, Dilma está individualizada, apresentando-se no papel de protagonista das ações governamentais que estruturam e sustentam a vida sociopolítica dos brasileiros.

Em relação ao segundo questionamento: qual o resultado que a ação representacional da chefe de governo constituiu diante de um cenário marcado por crise política, econômica e social?; de acordo com o estudo empreendido, sobre como se configurou a representação social da presidenta da República, no ano de 2015, compreendi que sua ação representacional se levanta, também, como um movimento de resistência em meio a um cenário repleto de adversidades e fortemente contrário à sua atuação político-social.

Baseado nisso, é que a representação de dupla face foi constituída. Dilma Rousseff decidiu fortalecer sua imagem de mulher brasileira, atuou para transmitir a ideia e o sentimento de que ela era semelhante aos demais cidadãos e, por isso, todos faziam parte de um grande grupo, mas ela era a líder.

Com isso, o caminho era preparado para que ela conseguisse adesão e sucesso da realização de seus propósitos por meio da construção da representação de governo federal forte, humano, capacitado e, em certa medida, heroico, resistente em meio às lutas, devido a isso conquistaria vitórias para o povo brasileiro.

\section{Considerações...}

As constatações alcançadas nesta pesquisa podem ser vistas como contribuições que servem para conduzir os atores sociais brasileiros à mudança de suas ações e de seus posicionamentos em relação à prática política. Isso se torna possível porque esta pesquisa expôs as ricas possibilidades que o discurso possui, sobretudo o político. Assim, as análises permitem compreender que é por meio do discurso que os políticos constroem representações sociais e imagens de suas atuações de acordo com determinadas motivações e propósitos ideológicos, com vistas a estabelecer e a manter relações de dominação ou, ainda, de constituir e fortalecer uma identidade de resistência diante de um contexto de crise.

Portanto, a questão maior não é gostar ou não de política, mas considerar que os discursos, as representações sociais e as construções ideológicas promovidas pelos atores políticos influenciam e cumprem propósitos que, muitas vezes, não correspondem com 
os dos cidadãos que os elegeram. Nesse sentido, é vital que os brasileiros assumam o protagonismo da cena política, adotando postura mais reflexiva e crítica nas práticas sociodiscursivas das quais eles participam. Dessa forma, a mudança necessária, em cada âmbito da vida sócio-política, pode ser melhor e mais significativamente promovida.

\section{Referências}

BAUER, M. W.; GASKELL, G. Pesquisa qualitativa com texto, imagem e som. Um manual prático. 2. ed. Petrópolis: Vozes, 2015.

ChARAUdEAU, P. Discurso Político. São Paulo: Contexto, 2015.

FAIRCLOUGH, N. Analysing Discourse: Textual analysis for social research. London, New York: Routledge, 2003.

Discurso e mudança social. Izabel Magalhães Coord. da tradução. Brasília: Editora Universidade de Brasília, 2001.

FARR, R. M. Representações sociais:a teoria e sua história. In: GUARESCHI, Pedrinho; JOVCHELOVITCH, S. (Org.). Textos em representações sociais. Petrópolis: Vozes, 2013. FLICK, U. Uma introdução à pesquisa qualitativa. Tradução de S. Netz. 2.ed. Porto Alegre: Bookman, 2004.

GUARESCHI, P.; JOVCHELOVITCH, S. Introdução. In: GUARESCHI, Pedrinho; JOVCHELOVITCH, S. (Org.). Textos em representações sociais. Petrópolis: Vozes, 2013. JOVCHELOVITCH, S. Vivendo a vida com os outros: intersubjetividade, espaço e público e representações sociais. In: GUARESCHI, Pedrinho; JOVCHELOVITCH, S. (Org.). Textos em representações sociais. Petrópolis: Vozes, 2013.

MINAYO, M. C. de S. O conceito de representações sociais dentro da sociologia clássica. In: GUARESCHI, Pedrinho; JOVCHELOVITCH, S. (Org.). Textos em representações sociais. Petrópolis: Vozes, 2013.

OLIVEIRA, E. A. C. O discurso sobre as mulheres fruta no jornal Folha de São Paulo: novas formas de comodificação do feminino na modernidade tardia. X ENCONTRO DO CELSUL - Círculo de Estudos Linguísticos do Sul UNIOESTE. 1. 2012. Cascavel (PR). Anais do X ENCONTRO DO CELSUL - Círculo de Estudos Linguísticos do Sul UNIOESTE. Cascavel: Universidade Estadual do Oeste do Paraná Cascavel-PR, 2012.

PEDRO, E. R. (Org.). Análise Crítica do Discurso: aspectos teóricos, metodológicos e analíticos. In: PEDRO, E. R. Análise Crítica do Discurso. Uma perspectiva funcional e analítica. Lisboa: Editora Caminho, 1998. 
VAN LEEUWEN, T. A representação dos actores sociais. In: PEDRO, Emília R. Análise Crítica do Discurso. Lisboa: Caminho, 1998. 